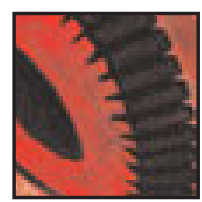

Ideas At Work

\title{
Innovations in \\ Healthcare Food Services
}

by Paul Gauntley

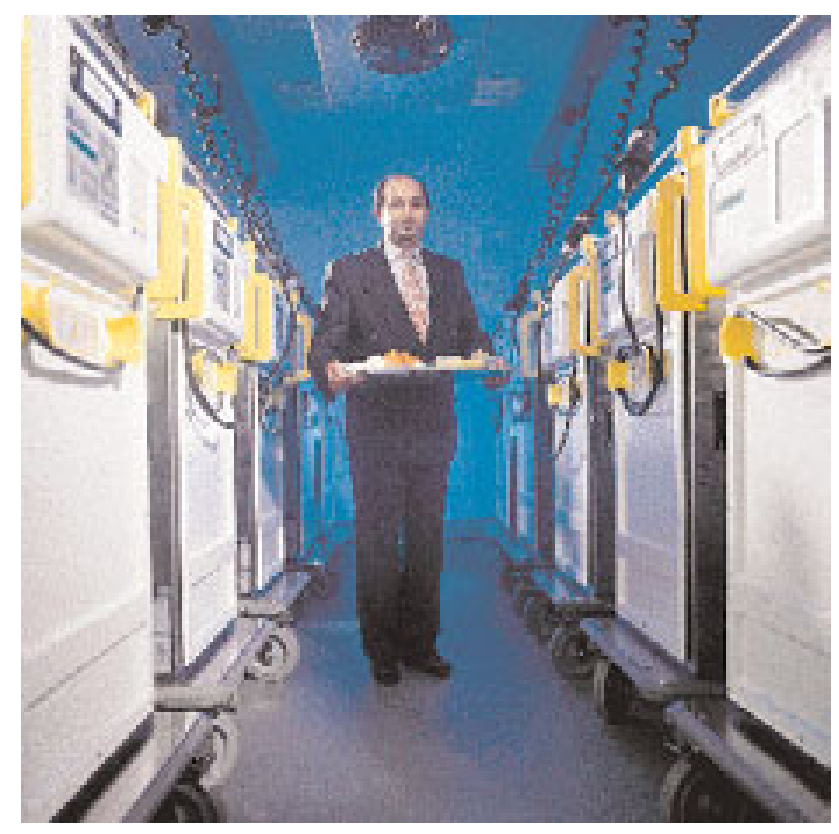

Narendra Shah, VP, Planning \& Support Services in the rethermalization room

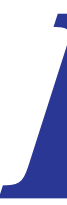

$\mathrm{n}$ the late 1980s, following discussions with clients, legislative bodies and healthcare experts across Canada, Versa Services identified the primary challenges healthcare managers were facing in the delivery of dietary services.

- Equipment in many hospital kitchens is outdated and food cannot be stored, prepared, or served in an efficient and sanitary manner. This leads to compromised storage space and temperatures, sub-standard production yields, inefficient staff, and inflexible meal service formats

- High maintenance and repair costs result from the use of older equipment. Many hospital kitchens require renovation and equipment replacement to ensure that equipment malfunction does not impede meal service

- Inappropriate food-serving temperatures due to centralized hot-plating techniques are omnipresent in many institutional dietary services. Moreover, the tray systems often cannot maintain adequate food temperatures from the central plating location to the point of service.

- Inconsistent skill levels of staff has always been an issue. For example, the Shepherd's Pie made by Chef A on Monday may not taste the same as the 
Shepherd's Pie made by Chef B next Monday

- Patient dissatisfaction with services is becoming more prevalent. In addition, old methods of meal delivery and menu design are not keeping up with the expectations of today's clientele

- Kitchen facilities are underutilized because the original architectural designs called for considerable space allocation and because of shrinking in-patient loads. In today's kitchens less space is required and in some cases (depending on the amount of food production done on-site) a "kitchen" is not needed at all, thus enabling a hospital to reclaim space for other uses

- The need for self-sustaining cafeterias is becoming more of an issue. Hospitals simply cannot afford to subsidize these operations any longer. In order to be profitable, cafeterias must win back the "brown bag" customer and entice visitors to the hospital.

- Future regionalization and consolidation must be at the forefront when developing new approaches to meal preparation and service. The challenge is to reengineer today while reducing potential redundancy for tomorrow.

- Reduced allocation of public funds brings with it caution about capital projects. Often there is a need to forgo kitchen renovation projects for other "front of the house" needs or medical equipment. Solutions that push the envelope and consider a "kitchenless" orientation are becoming more prevalent today.

\section{Is Food Outsourcing THE ANSWER?}

Many believe that food outsourcing (or purchasing prepared entrees, starches, desserts etc. from reputable food manufacturers) can generate considerable savings. This is true up to a point. Versa's experience with "kitchenless" or outsourced food projects indicates that operators, who adopt food outsourcing to augment their department reengineering initiatives, have realized up to $6 \%$ budget reductions while also enhancing food quality. Moreover, the ability to avoid the capital investment required to replace outdated production equipment is often a precursor to adopting food outsourcing.

However, Versa has learned from the projects it has implemented that it is the introduction of coldmeal-assembly principles, and the departure from hot-belt lines and insulated trays that offer the most sustainable savings (up to 12-16\%). This is because cold-meal assembly allows a team to prepare meal trays in advance using one shift of employees around a belt line rather than the shift-and-a-half required for a hot-belt line. The chilled meals are then reheated (rethermalized) later in the day, close to service, in specialized stateof-the art meal carts.

This raises the question, "What should come first - food outsourcing or new tray assembly and delivery systems?" The answer is that each can exist separately, however, coupling these approaches leads to improved flexibility, and considerable savings (Versa clients are realizing up to $18-22 \%$ in savings and in some cases higher). Moreover, by combining these solutions, there is an increase in menu item consistency and more control of food cost. Less money is spent on repairs and maintenance of kitchen equipment. The appearance of food trays improves and food temperature is more consistent. Finally, there is more flexibility in meal service times.

\section{The Riverside Hospital - A Progressive Case Study} The Riverside Hospital of Ottawa is a 220-bed acute-care facility that has contracted Versa to manage their dietary and housekeeping services since July, 1984. The Riverside recently embraced a food outsourcing and cold-plating approach that has resulted in a $30 \%$ operational savings in its food service budget.

In the early 1990s the hospital was faced with a kitchen fastapproaching obsolescence. Cooking equipment was malfunctioning, and health and safety challenges in the kitchen were becoming more of an issue. The kitchen needed to be reno- 
vated to meet modern standards.

The hot-belt line was not ergonomically sound, and hot trays prepared-centrally in the kitchen were not

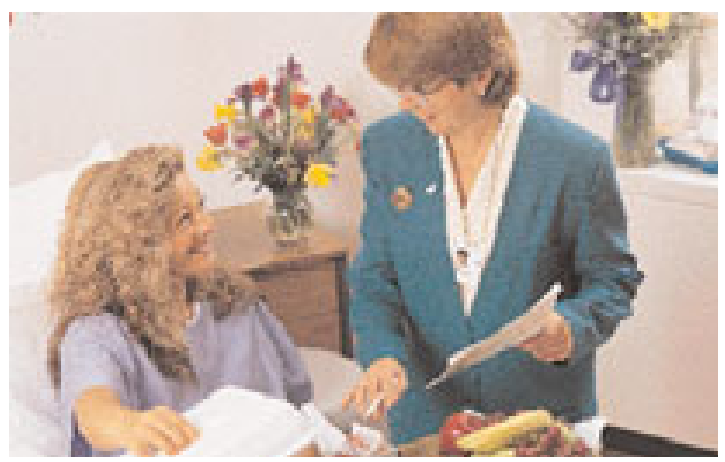

Nutrition Services Director Marian Neeson with Riverside patient

keeping food enough levels to the bedside. Versa investigated many options to reengineer the food services department and temperatures at high withstand the distribution time to presented a business case to the hospital for review.

The solution? Eliminate the kitchen entirely. In partnership with Versa, the hospital introduced a whole new technology: cold

The Riverside Hospital Dietary Department Before REENGINEERING

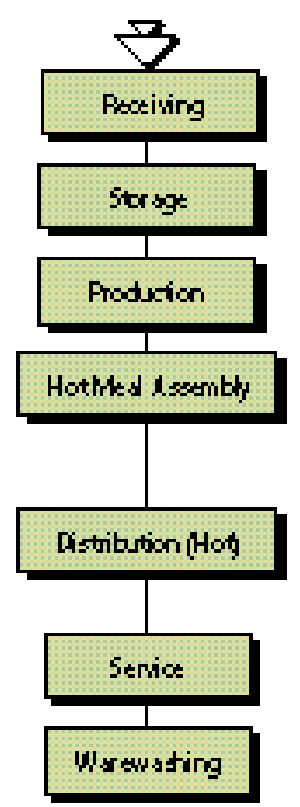

plating using outsourced foods. Implemented in November, 1996, the system uses retherm carts purchased from Grand Cuisine Systems Inc. The retherm carts reheat chilled entrees and soups on the same tray that is presented to the patient. Versa manages the Nutrition Services Department and prepares the trays on-site for the now "kitchenless" hospital.

"Riverside achieved immediate savings of $30 \%$ when compared to 1996 budget with this new system," says Narendra Shah, Vice President of Planning and Support Services at the hospital. "In terms of weighted costs per patient day, Riverside's food service operation ranks within the top $10 \%$ of Ontario hospitals," he adds.

In the new system, individual

The Riverside Hospital Dietary Department After REENGINEERING

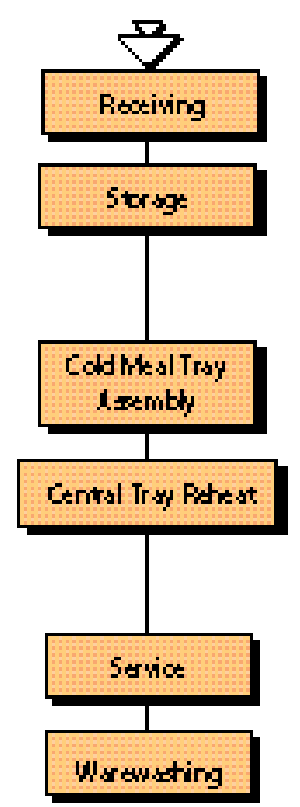


food trays are assembled using outsourced foods from reputable food suppliers. The trays are prepared as close to delivery time as possible in a $10 \mathrm{C}$ environment. Once each 20 tray cart is full, it moves to the $3 \mathrm{C}$ rethermalization room. While being held inside the cart, one side of each tray is rethermalized while the other side remains cold. Since the new system has been in place the hospital has seen patient satisfaction surveys related to Nutrition Services increase to $93 \%$.

While the reengineering initially required a \$700,000 investment, the planned annual savings of $\$ 425,000$ is on track, thus providing a payback in less than two years. The investment included asbestos removal and kitchen renovations to install new flooring and a cold room for tray assembly. In addition, the investment included the purchase of the new cold tray and meal delivery system.

Versa serves approximately 600700 patient meals a day at the Riverside Hospital and delivers meals to the patient bedside. A review of the original business case shows that the total number of fulltime employees (FTEs) related to patient services (excluding Clinical Nutrition) was once 27.56. With the new system in place analysis of the operation confirms the business case as the FTE compliment is now 18.71. The rethinking of dietary services has increased the level of efficiency in the department from 2,648 annual patient meal days per
FTE to 3,900 annual patient meal days per FTE. This is a $47 \%$ increase in efficiency.

\section{LESSONS LEARNED}

While the solution found for the Riverside Hospital of Ottawa has improved patient care and provided annual savings that financed the investment, it must be made clear that this specific solution may not be the answer for every hospital. Individual hospitals have unique challenges, and solutions are required that meet the needs of each specific location or grouping of locations. For example, Versa recently installed a new meal delivery system using outsourced foods at one hospital so that it can provide meals to another hospital. The system was customized to meet the challenges of regionalization.

Another Versa project has outsourced food being used, but delivery of meals is being done in a bulk service format. This system was adopted so that Versa could improve the quality of service to meet the unique needs of the children hospitalized in

the facility.

The merits of food outsourcing, and new meal plating and delivery systems are proven; it is the manner in

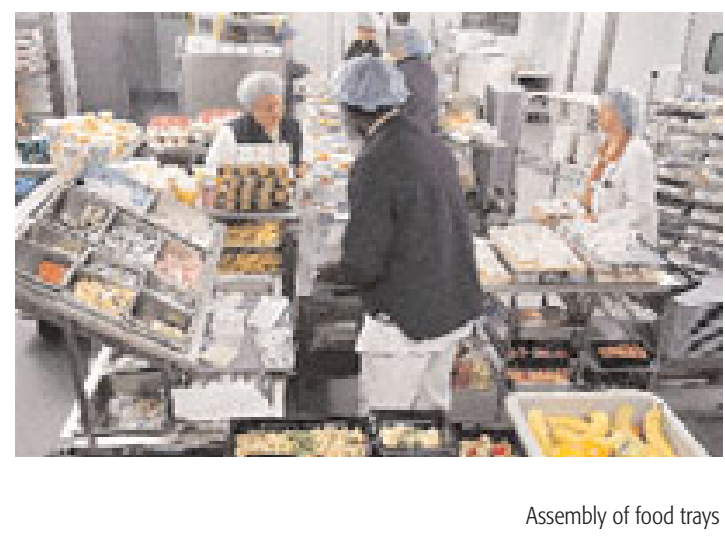
which these new resources are used to reinvent the food service department that is the crucial piece of the puzzle.
Paul Gauntley is National Director of Technical Services for Versa's Healthcare Services Division. As a leading provider of support community, Versa Healthcare Services has considerable experience in partnering with hospitals to develop customized processes that reduce costs, improve quality and maximize operating efficiency. services to Canada's healthcare 